\title{
Treatment of intrathoracic anastomotic leak after esophagectomy with the sump drainage tube
}

\author{
Qifan Yin, Shaohui Zhou, Yongbin Song, Xuejiao Xun, Nana Liu and Lijun Liu*
}

\begin{abstract}
Background: Intrathoracic esophagogastric anastomotic leak is one of the deadliest complications after esophagectomy. In recent years, we have implemented new method for the treatment of intrathoracic esophagogastric anastomotic leak with the nasogastric placement of sump drainage tube through fistula into abscess cavity. The aim of this study is to compare the efficacy of the new method and conventional therapies for intrathoracic anastomotic leak after esophagectomy.

Method: Esophagectomy and esophagogastric anastomotic procedures were performed in 875 patients at our institution from January 2008 to December 2019. Of these patients, 43(4.9\%) patients developed intrathoracic anastomotic leaks postoperatively were enrolled into our study and their clinical data were retrospectively assessed. 20 (47\%) patients from January 2008 to December 2012 received conventional treatments (group 1) known as the traditional "three-tube method", and 23 (53\%) patients from January 2013 to December 2019 received new treatments (group 2), consisted of conventional therapies and the nasogastric placement of sump drainage tube through fistula into abscess cavity.
\end{abstract}

Results: The presence of intrathoracic anastomotic leak was proven by contrast esophagography in 43 patients (4.9\%). Among them, The average duration of chest tube was 47 days in group 1 and 28 days in group 2. The average length of leak treatment was 52 days in group 1 and 35 days in group 2. The average length of postoperative hospital stay was 56 days in group 1 and 39 days in group 2, respectively. 7(35\%) patients among 20 patients died from intrathoracic anastomotic leak in group 1; and 3(13\%) patients among 23 patients died from intrathoracic anastomotic leak in group 2. Compared with the conventional treatments (group 1), The average duration of chest tube was significantly decreased in the new treatments (group 2$)(P<0.01)$, as well as the length of leak treatment $(P<0.05)$ and the length of postoperative hospital stay $(P<0.01)$. However, there was no significant difference in the mortality rate $(P=0.148>0.05)$.

Conclusion: In conclusion, Our results showed this method of the nasogastric placement of sump drainage tube through fistula appears to be an safe, effective, technically feasible treatment option for intrathoracic esophagogastric anastomotic leak. The efficacy and feasibility could be further investigated with a well-designed and large-scale RCT research.

Keywords: Intrathoracic anastomotic leak, Esophagectomy, Sump drainage tube

\footnotetext{
* Correspondence: LijunLiu8176@163.com

Department of Thoracic Surgery, Hebei General Hospital, 348, West He-Ping

Road, Shijiazhuang 050051, Hebei Province, People's Republic of China
}

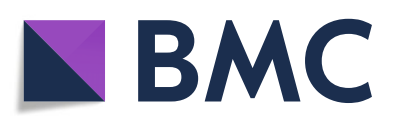

(- The Author(s). 2021 Open Access This article is licensed under a Creative Commons Attribution 4.0 International License, which permits use, sharing, adaptation, distribution and reproduction in any medium or format, as long as you give appropriate credit to the original author(s) and the source, provide a link to the Creative Commons licence, and indicate if changes were made. The images or other third party material in this article are included in the article's Creative Commons licence, unless indicated otherwise in a credit line to the material. If material is not included in the article's Creative Commons licence and your intended use is not permitted by statutory regulation or exceeds the permitted use, you will need to obtain permission directly from the copyright holder. To view a copy of this licence, visit http://creativecommons.org/licenses/by/4.0/. The Creative Commons Public Domain Dedication waiver (http://creativecommons.org/publicdomain/zero/1.0/) applies to the data made available in this article, unless otherwise stated in a credit line to the data. 


\section{Introduction}

Esophageal cancer is one of the most common malignant tumors in China. The new cases have reached 250,000 a year, accounting for more than half of the 480,000 cases worldwide [1]. Radical surgery remains the optimal treatment option for resectable esophageal tumors [2]. Anastomotic leak is one of the deadliest complications to occur after esophagectomy [3, 4]. The incidence of anastomotic leak is $10-25 \%$ at the cervical region, but mortality rate in this region is low [5-7]. In the literature, the incidence of intrathoracic anastomotic leaks is $3-25 \%$ and the mortality rate is $30-60 \%$ [8-10]. Approximately $40 \%$ of general postoperative mortality rate is related to esophagogastric anastomotic leaks [11]. Intrathoracic esophagogastric anastomotic leak after esophagectomy is still a significant cause of postoperative morbidity and mortality [12]. The most effective treatment option for intrathoracic esophagogastric anastomotic leak is still controversial, and there is no standard treatment. Some surgeons recommend aggressive surgery, while others prefer conservative treatments, such as perianastomotic drainage, total parenteral nutrition, nasogastric decompression, and use of broadspectrum antibiotics $[13,14]$. With the development of interventional radiology and endoscopic therapy, we have implemented new method for the treatment of intrathoracic esophagogastric anastomotic leak with the nasogastric placement of sump drainage tube through fistula into abscess cavity. The aim of this study is to compare the efficacy of the new method and conventional therapies for intrathoracic esophagogastric anastomotic leak after esophagectomy for esophageal or esophagogastric junction carcinoma.

\section{Patients and methods \\ Patients}

Esophagectomy and esophagogastric anastomotic procedures were performed in 875 patients for esophageal or esophagogastric junction cancer at our institution of Hebei General Hospital from January 2008 to December 2019. Of these patients, 56 (6.4\%) patients were diagnosed with anastomotic leak. Thirteen patients were excluded because of simplex cervical anastomotic leaks, who were cured by opening of the wound and daily irrigation and packing. Eventually, 43(4.9\%) patients developed intrathoracic anastomotic leaks postoperatively were enrolled into our study and their clinical data were retrospectively evaluated. All of them developed mediastinitis and empyema. Twenty-three cases underwent an McKeown esophagectomy with cervical anastomosis, 8 cases underwent an Ivor-Lewis esophagectomy and 12 cases underwent a Sweet esophagectomy with intrathoracic anastomosis. Twenty-eight patients had esophageal cancer and 15 patients had esophagogastric junction cancer. Twenty-eight male and 15 female, age from 52 to 74 , average age $64.5 \pm 4.7$. The stomach was mobilized and was used as a standard organ to reconstruct the continuity of the digestive tract in all patients. The anastomosis was performed via staplers in all 43 patients. The patients were divided into two groups according to the different treatments they received. 20 (47\%) patients from January 2008 to December 2012 received conventional treatments (group 1), and 23 (53\%) patients from January 2013 to December 2019 received new treatments (group 2), consisted of conventional therapies and the nasogastric placement of sump drainage tube through fistula into abscess cavity. Anastomotic leak was detected and confirmed by radiographic water-soluble iodine contrast esophagography when leak was under suspicion. The median time to confirmation of a significant leak was 6 days after surgery (range, 3-9 days). In all patients with intrathoracic anastomotic leaks, conservative treatment strategies were chosen, consisted of absence of oral intake, nasogastric suction drainage, enteral nutrition, antibiotic therapy, and drainage of the infected material through chest tube. This study was reviewed and approved by the institutional review board of the Hebei General Hospital.

The following patient characteristics were reviewed: age, gender, pathologic findings, chemoradiotherapy history, accompanying diseases, operation method, type of anastomosis location, timing of diagnosis and treatment of the leak, hospital mortality, and duration of hospitalization. The basic characteristics of the enrolled patients were shown in Table 1.

\section{Operation and postoperative care}

For all patients, esophagectomy and esophagogastric anastomosis were performed. We used a circular mechanical stapler for anastomosis. A nasogastric decompression tube and thoracic and mediastinal drainage tubes were routinely placed during the procedure. The intubated patients were monitored in intensive care unit postoperatively. Following extubation, all patients stayed in intensive care unit for at least $24 \mathrm{~h}$. The patients who were stable were transferred to our thoracic surgical ward. All patients were treated with fasting, gastrointestinal decompression, parenteral nutrition, antacids, and broad-spectrum antibiotics. If the clinical situation of the patient was stable, Water-soluble iodine contrast esophagography wloud be routinely performed on the 5th-7th postoperative day. If purulent drainage, fever, dyspnea, empyema, or wound infection possibly related to fistula were observed, Water-soluble iodine contrast esophagography was given immediately in order to confirm anastomosis leakage. When anastomotic leak was confirmed, all patients were placed with naso-jejunum three lumen feeding tube under the radiographic or 
Table 1 The patients characteristics

\begin{tabular}{|c|c|c|c|}
\hline Patients' characteristics & Conventional treatments (group 1) $(n=20)$ & New treatments (group 2) $(n=23)$ & $P$ value \\
\hline Age & $64.2 \pm 4.8$ & $65.1 \pm 4.2$ & $P=0.259$ \\
\hline \multicolumn{4}{|l|}{ Gender } \\
\hline Male & 12 & 16 & \multirow[t]{2}{*}{$P=0.733$} \\
\hline Female & 8 & 7 & \\
\hline \multicolumn{4}{|l|}{ Cancer type } \\
\hline Esophageal cancer & 13 & 15 & \multirow[t]{2}{*}{$P=0.780$} \\
\hline Esophagogastric junction cancer & 7 & 8 & \\
\hline Neoadjuvant chemotherapy & 5 & 6 & $P=0.936$ \\
\hline \multicolumn{4}{|l|}{ Comorbidity } \\
\hline Hypertension & 6 & 7 & $P=0.895$ \\
\hline Diabetes & 4 & 5 & $P=0.936$ \\
\hline \multicolumn{4}{|l|}{ Anastomosis location } \\
\hline Cervical anastomosis & 8 & 15 & \multirow[t]{2}{*}{$P=0.818$} \\
\hline Intrathoracic anastomosis & 10 & 8 & \\
\hline \multicolumn{4}{|l|}{ Operation method } \\
\hline McKeown esophagectomy & 8 & 15 & \multirow[t]{3}{*}{$P=0.611$} \\
\hline Ivor-Lewis esophagectomy & 4 & 4 & \\
\hline Sweet esophagectomy & 6 & 4 & \\
\hline Timing of diagnosis & 6.3 & 5.8 & $P=0.09$ \\
\hline
\end{tabular}

gastroscopic guidance. This tube not only ensures enteral nutrition, but also provides gastrointestinal decompression (Figs. 1b; 2b). If there was no fever, leukocytosis, dyspnea, purulent drainage, the chest tube was removed. The mediastinal drainage tube was not

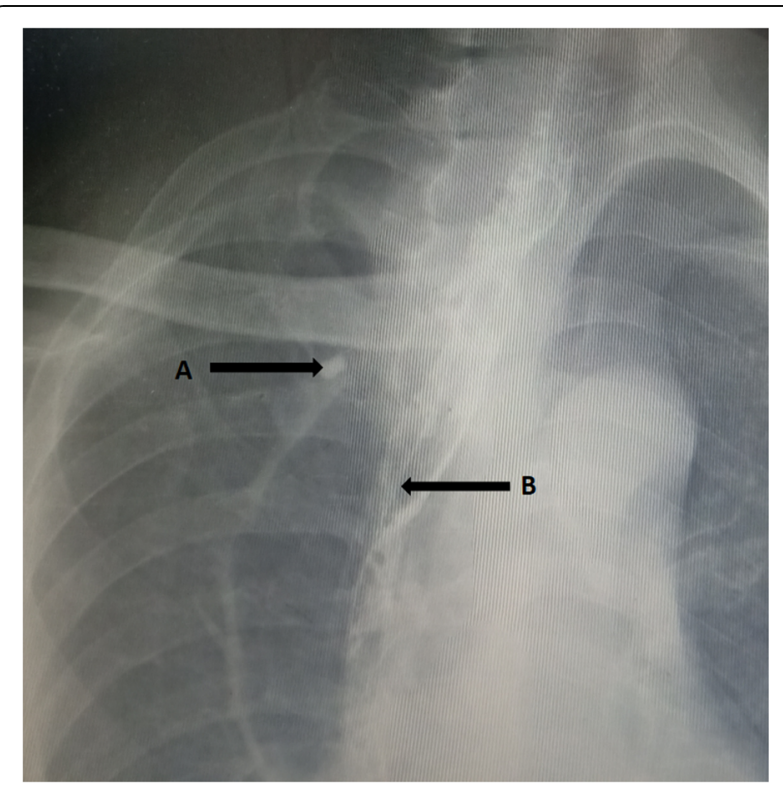

Fig. 1 The image of contrast esophagography removed until oral feeding. All patients were followed up for at least 6 months in the outpatient department.

\section{Conventional managements (group 1)}

20 (47\%) patients from January 2008 to December 2012 received conventional treatments (group 1). when intrathoracic anastomosis leak was confirmed, naso-jejunum three lumen feeding tube was placed under the radiographic or gastroscopic guidance. The functions of this tube include nasogastric decompression and nasojejunum enteral nutritional support. The chest drainage tubes should usually be placed under the guidance of ultrasonography. These patients were treated by the traditional "three-tube method", consisting of feeding tube, gastrointestinal decompression tube and chest drainage tube. In addition, other treatments, such as fasting, broad spectrum antibiotics and antacids, were routinely performed. When the patients became stable, a contrast esophagography was performed every other week. Those patients whose leaks are confirmed to have been healed radiologically may start oral feeding.

\section{New managements (group 2)}

23 (53\%) patients from January 2013 to December 2019 received new treatments (group 2). Intrathoracic anastomotic leak was identified by radiographic water-soluble iodine contrast esophagography when leak was under suspicion. In addition to the conventional treatments 


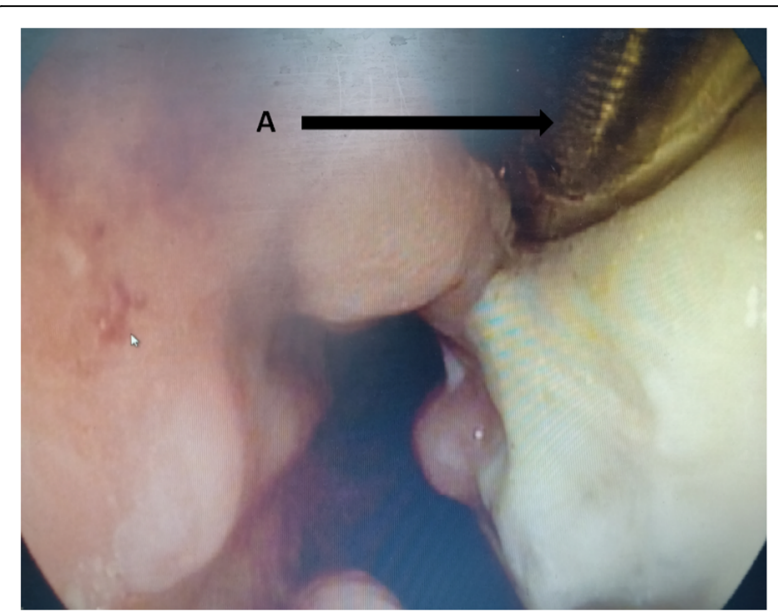

Fig. 2 The gastroscopy after removal of sump drainage tube. a Nasogastric sump drainage tube (a) was inserted through the fistula with the guidance of radiography or gastroscopy and the distal tip of the tube was positioned at the bottom of the abscess cavity. $\mathbf{b}$ Naso-jejunum three lumen feeding tube (b) was placed under the radiographic or gastroscopic guidance. The functions of this tube include nasogastric decompression and nasojejunum enteral nutrition. c The closed fistula

previously described, A sump drainage tube was introduced through the nose, remanet esophagus and inserted through the fistula into mediastinum with the guidance of radiography or gastroscopy. The distal tip of the sump drainage tube should be positioned at the bottom of the abscess cavity (Figs. 1a; 3a). Continuous suction with a negative pressure should be achieved for effective drainage. Contrast esophagography should be repeated once a week for treatment effect evaluation. The nasogastric sump drainage tube was used as the

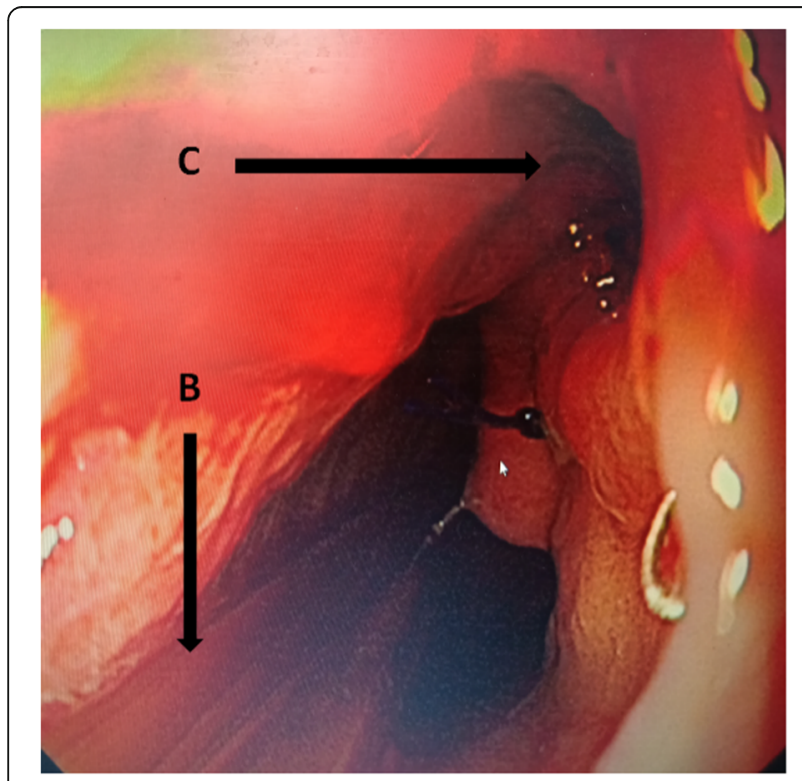

Fig. 3 The gastroscopy during treatment perianastomotic drain, which had multiple side holes. The drain position was checked under radiography by the injection of contrast medium through the tube. When the reduction of the cavity size was observed, the sump drainage tube was then retreated gradually. The sump drainage tube was pulled of $1-2 \mathrm{~cm}$ every $2-3$ days until the tip of the tube was retreated to the esophageal cavity, the tube was removed. After termination of therapy, Contrast esophagography was performed once again to confirm the closure of the anastomotic leak. Thereafter, oral intake was gradually started.

\section{Statistical analysis}

Statistical analysis was performed with SPSS version 21.0 software (IBM Corporation, Armonk, NY). Continuous variables were expressed as the means $\pm \mathrm{SD}$, and categorical variables were expressed as percentages. A two independent samples $t$ test was used for intergroup comparisons of the continuous variables, whereas $\mathrm{X}^{2}$ test or Fisher's exact test was used to compare the categorical data. All tests were two-sided, $P<0.05$ was considered statistically significant.

\section{Results}

From January 2008 to December 2019, 875 patients received esophagectomy and esophagogastric anastomotic procedures in our department. The presence of intrathoracic anastomotic leak was confirmed by contrast esophagography in 43 patients (4.9\%). Among them, 20 patients were treated by conventional treatments (group 1) known as the traditional "three-tube method". Twenty-three patients were managed by new treatments (group 2), consisted of conventional therapies and the nasogastric placement of sump drainage tube through fistula into abscess cavity.

There were no significant differences in the mean age, gender, cancer type, neoadjuvant chemotherapy or comorbidities between the two groups $(P>0.05)$. The anastomosis location, operation method, and timing of diagnosis in the new treatments (group 2) were also similar compared with the conventional treatments (group 1) $(P>0.05)$. The details are summarized in Table 1 . The postoperative data of the enrolled patients were shown in Table 2.

\section{Duration of chest tube}

The average duration of chest tube was 47 days in group 1 and 28 days in group 2, respectively. The minimum duration of chest tube was 36 days in group 1 and 23 days group 2, the maximum duration of chest tube was 54 days in group 1 and 42 days group 2, respectively. 
Table 2 Postoperative data collection

\begin{tabular}{|c|c|c|c|}
\hline Postoperative observed indicators & Group $1(n=20)$ & Group $2(n=23)$ & $P$ value \\
\hline \multicolumn{4}{|l|}{ Duration of chest tube } \\
\hline Average & 47 days & 28 days & $P=0.000$ \\
\hline Range & $36-54$ days & $23-42$ days & \\
\hline \multicolumn{4}{|l|}{ Length of leak treatment } \\
\hline Average & 52 days & 35 days & $P=0.01$ \\
\hline Range & 40-61 days & $28-52$ days & \\
\hline \multicolumn{4}{|l|}{ Length of postoperative hospital stay } \\
\hline Average & 56 days & 39 days & $P=0.000$ \\
\hline Range & 45-70 days & $32-54$ days & \\
\hline Hospital mortality & $7(35 \%)$ & $3(13 \%)$ & $P=0.148$ \\
\hline
\end{tabular}

\section{The length of leak treatment}

The average length of leak treatment was 52 days (range, 40-61 days) in group 1 and 35 days (range, 28-52 days) in group 2, respectively.

\section{The length of postoperative hospital stay}

The average length of postoperative hospital stay was 56 days, ranging from 45 to 70 days in group 1 and 39 days, ranging from 32 to 54 days in group 2, respectively.

\section{Hospital mortality}

7 (35\%) patients among 20 patients died from intrathoracic anastomotic leak in group 1; and 3 (13\%) patients among 23 patients died from intrathoracic anastomotic leak in group 2.

Compared with the conventional treatments (group 1), The average duration of chest tube was significantly decreased in the new treatments (group 2) $(P<0.01)$, as well as the length of leak treatment $(P<0.05)$ and the length of postoperative hospital stay $(P<0.01)$. However, there was no significant difference in the mortality rate $(P=0.148>0.05$; Table 2$)$.

\section{Discussion}

Intrathoracic esophagogastric anastomotic leak is one of the most serious complications after esophagectomy due to its associated high postoperative morbidity and mortality rates $[15,16]$. In our study, the intrathoracic anastomotic leaks occurred in $4.9 \%$ of our patients, which was slightly lower than the reported incidence [13, 17]. This may be explained by our general treatment preference for staplers in the anastomosis, interrupted hand sutures for reinforcement.

Due to this wide clinical spectrum, the most effective treatment approach in introthoracic anastomotic leak is controversial. There is no standard treatment method especially for patients with symptomatic thoracic leaks. Gastric fluid has digestive properties that make leakage extremely noxious. Anaerobic bacteria from the patient's oral cavity and swallowed saliva will cause a virulent tissue reaction and infection that can result in mediastinitis, empyema, or multiple organ failure. Generally speaking, fasting and decompressing the conduit with a nasogastric tube, parenteral or enteral nutrition and broad-spectrum antibiotics are basic steps once intrathoracic anastomotic leaks confirmed. Adequate drainage of infected fluid is much more necessary. This may include appropriately positioned chest drainage tubes to encourage full expansion of the lung. But it is often not enough, especially when pus is divided and mediastinitis is very serious. Leak from an anastomosis may lead to the formation of a perianastomotic abscess. So perianstomotic drain is very vital. The nasogastric sump drainage tube through fistula into abscess cavity was used as the perianastomotic drain under the guidance of radiography or gastroscopy, which could sufficiently drain purulent fluid nearby the anastomosis and prevent continuous contamination. Daily irrigation will be recommended when the abscess content is extremely viscid and thick. Maintenance of nutrition and complete drainage will allow granulation tissue to grow in this area and produce closure of the fistula. All patients were placed with nasojejunum three lumen feeding tubes that not only ensure sufficient enteral nutrition, but also provide adequate gastrointestinal decompression in our study.

Conservative managements were usually performed in contained intrathoracic esophagogastric anastomotic leaks. The traditional "three-tube method" was the most widely applied method in Chinese thoracic clinics [18]. The principle of this method was effective chest tube drainage. Usually, a 24F chest tube was placed into the abscess under the guidance of CT scan or ultrasonography. When the abscess was limited in the pleural cavity, this method could achieve adequate drainage. But previous studies had reported that most of the contained leaks were limited to the mediastinum $[13,15]$. It is difficult to deal with this type of leakage because abscess cavities close to the mediastinum are difficult to reach 
by the conventional chest tube. The nasogastric placement of sump drainage tube through the fistula in our study may be a helpful treatment for this type of leak. We successfully applied the nasogastric placement of sump drainage tube through the fistula for the treatment of intrathoracic anastomotic leaks in 23 patients. Compared with the conventional treatments of "three-tube method," this management could achieve better drainage due to precise positioning and continuous negative pressure suction. Our study showed that the average length of leak treatment was 52 days in group 1 and 35 days in group 2. The average length of postoperative hospital stay was 56 days in group 1 and 39 days in group 2.Statistical analysis revealed that the treatment of nasogastric placement of sump drainage tube through the fistula may result in significantly shortened the length of leak treatment and hospitalization. In addition, these two treatment groups, mentioned above, had similar mortality rates according to our clinical results, ranging from 13 to $35 \%$, which were considered acceptable according to previous studies $[19,20]$.

\section{Conclusion}

In conclusion, Our results showed this method of the nasogastric placement of sump drainage tube through fistula appears to be an safe, effective, technically feasible treatment option for intrathoracic esophagogastric anastomotic leak. The efficacy and feasibility could be further investigated with a well-designed and large-scale RCT research.

\section{Abbreviations \\ CT: Computed Tomography; SD: Standard Deviation; RCT: Randomized Controlled Trail}

\section{Acknowledgements}

The authors would like to thank professor Lijun Liu's attempt in the application of the nasogastric placement of sump drainage tube through fistula for intrathoracic esophagogastric anastomotic leak and all colleagues in the department of thoracic surgery for their support to our research.

\section{Authors' contributions}

Lijun Liu conceived the study. Shaohui Zhou, Yongbin Song collected the data, Xuejiao Xun, Nana Liu analysed the data and performed statistical analyses. Qifan Yin drafted the manuscript. Lijun Liu gave important intellectual contribution and critically revised the manuscript. Shaohui Zhou, Yongbin Song followed up all the enrolled patients. All authors read and approved the final manuscript.

\section{Funding}

No funding was involved in this study.

\section{Availability of data and materials}

The datasets used and analysed during the current study are available from the corresponding author on reasonable request.

\section{Declarations}

\section{Ethics approval and consent to participate}

This study conforms to the ethical guidelines in a priori approval by the local Ethical Committee of the Hebei General Hospital. Our research was approved by Ethical Committee of the Hebei General Hospital. All enrolled patients signed informed consent.

Consent for publication

Not applicable.

\section{Competing interests}

There was no competing interests.

Received: 28 September 2020 Accepted: 16 March 2021

Published online: 23 March 2021

\section{References}

1. Chen W, Zheng R, Baade PD, Zhang S, Zeng H, Bray F, Jemal A, Yu XQ, He J. Cancer statistics in China, 2015. CA Cancer J Clin. 2016;66(2):115-32. https:// doi.org/10.3322/caac.21338.

2. Enzinger PC, Mayer RJ. Esophageal cancer. N Engl J Med. 2003;349(23):224152. https://doi.org/10.1056/NEJMra035010.

3. Liu JF, Wang QZ, Ping YM, Zhang YD. Complications after esophagectomy for cancer: 53-year experience with 20,796 patients. World J Surg. 2008;32(3): 395-400. https://doi.org/10.1007/s00268-007-9349-z.

4. Thompson AM, Park KG. Diagnosis and management of a mediastinal leak following radical oesophagectomy (Br J Surg 2001; 88: 1346-51). Br J Surg. 2002;89(6):810-1; discussion 811. https://doi.org/10.1046/j.1365-2168.2002. 02127_10.x.

5. Orringer MB, Marshall $B$, lannettoni MD. Transhiatal esophagectomy: clinical experience and refinements. Ann Surg. 1999;230(3):392-400; discussion 400393. https://doi.org/10.1097/00000658-199909000-00012.

6. Hankins JR, Attar S, Coughlin TR, et al. Carcinoma of the esophagus: a comparison of the results of transhiatal versus transthoracic resection. Ann Thorac Surg. 1989;47(5):700-5. https://doi.org/10.1016/0003-4975(89)901215.

7. Urschel JD. Esophagogastrostomy anastomotic leaks complicating esophagectomy: a review. Am J Surg. 1995;169(6):634-40. https://doi.org/1 0.1016/50002-9610(99)80238-4.

8. Blewett CJ, Miller JD, Young JE, Bennett WF, Urschel JD. Anastomotic leaks after esophagectomy for esophageal cancer: a comparison of thoracic and cervical an astomoses. Ann Thorac Cardiovasc Surg. 2001;7(2):75-8.

9. Patil PK, Patel SG, Mistry RC, Deshpande RK, Desai PB. Cancer of the esophagus: esophagogastric anastomotic leak--a retrospective study of predisposing fact ors. J Surg Oncol. 1992;49(3):163-7. https://doi.org/10.1 002/jso.2930490307.

10. Dehn TC, Menon K. Diagnosis and conservative management of intrathoracic leakage after oesophagectomy. Br J Surg. 1999;86(3):427. https://doi.org/10.1046/j.1365-2168.1999.1055e.X.

11. Alanezi K, Urschel JD. Mortality secondary to esophageal anastomotic leak. Ann Thorac Cardiovasc Surg. 2004:10(2):71-5.

12. Rizk NP, Bach PB, Schrag D, Bains MS, Turnbull AD, Karpeh M, Brennan MF Rusch WW. The impact of complications on outcomes after resection for esophageal and gastroesophageal junction carcinoma. J Am Coll Surg. 2004;198(1):42-50. https://doi.org/10.1016/j.jamcollsurg.2003.08.007.

13. Turkyilmaz A, Eroglu A, Aydin Y, Tekinbas C, Muharrem Erol M, Karaoglanoglu N. The management of esophagogastric anastomotic leak after esophagectomy for esophageal carcinoma. Dis Esophagus. 2009;22(2): 119-26. https://doi.org/10.1111/j.1442-2050.2008.00866.x.

14. Tam PC, Fok M, Wong J. Reexploration for complications after esophagectomy for cancer. J Thorac Cardiovasc Surg. 1989;98(6):1122-7. https://doi.org/10.1016/S0022-5223(19)34328-4.

15. Crestanello JA, Deschamps C, Cassivi SD, Nichols FC III, Allen MS, Schleck C, Pairolero PC. Selective management of intrathoracic anastomotic leak after esophagectomy. J Thorac Cardiovasc Surg. 2005;129(2):254-60. https://doi. org/10.1016/j.jtcvs.2004.10.024.

16. Whooley BP, Law S, Alexandrou A, Murthy SC, Wong J. Critical appraisal of the significance of intrathoracic anastomotic leakage after esophagectomy for c ancer. Am J Surg. 2001;181(3):198-203. https://doi.org/10.1016/S00029610(01)00559-1.

17. Fumagalli U, Baiocchi GL, Celotti A, Parise P, Cossu A, Bonavina L, Bernardi D, Manzoni G, Weindelmayer J, Verlato G, Santi S, Pallabazzer G, Portolani N, Degiuli M, Reddavid R, Pascale S. Incidence and treatment of mediastinal leakage after esophagectomy: insights from the multicenter stu dy on 
mediastinal leaks. World J Gastroenterol. 2019;25(3):356-66. https://doi.org/1 0.3748/wjg.v25.i3.356.

18. Ke H, Zhao H, Qiu X, Dong H, You Q. Improved three-tubing approach for the reoperation of perforation suturing anastomotic fistula after radical radiotherapy of upper thoracic esophgeal squamous cell carcinoma. J Thorac Dis. 2013;5(6):E240-2. https://doi.org/10.3978/j.issn.2072-1439.2 013.12.39.

19. Postlethwait RW. Complications and deaths after operations for esophageal carcinoma. J Thorac Cardiovasc Surg. 1983;85(6):827-31. https://doi.org/10.1 016/50022-5223(19)37470-7.

20. Hünerbein M, Stroszczynski C, Moesta KT, Schlag PM. Treatment of thoracic anastomotic leaks after esophagectomy with self-expanding plastic stents. Ann Surg. 2004;240(5):801-7. https://doi.org/10.1097/01.sla.0000143122. 76666.ae.

\section{Publisher's Note}

Springer Nature remains neutral with regard to jurisdictional claims in published maps and institutional affiliations.

Ready to submit your research? Choose BMC and benefit from:

- fast, convenient online submission

- thorough peer review by experienced researchers in your field

- rapid publication on acceptance

- support for research data, including large and complex data types

- gold Open Access which fosters wider collaboration and increased citations

- maximum visibility for your research: over $100 \mathrm{M}$ website views per year

At $\mathrm{BMC}$, research is always in progress.

Learn more biomedcentral.com/submissions 